\title{
MENGINTIP KONDISI CUACA PENYEBAB BANJIR BESAR DI DKI JAKARTA TANGGAL 25 OKTOBER 2010
}

\author{
M. Karmini' dan F. Renggono ${ }^{1}$
}

\begin{abstract}
Jakarta was struck by torrential rain at 16:00 pm. Standing water caused by heavy rain occured immediately. The rain lasted until around 20:00 pm. From the AWS measurement at Jatiwaringin, highest rainfall of $230 \mathrm{~mm}$ was recorded at 16:00 pm. Rainfall amount until 19:00 pm was recorded of about $650.60 \mathrm{~mm}$, in other words rainfall intensity was about $216.87 \mathrm{~mm} / \mathrm{hour}$ for the period of 16:00 - 19:00 pm. Some stability indices, which is calculated from rawinsonde at 07:00 am showed the potential for convective activity which could produce heavy rain. Some stability indices that show strong potential for convective process are: LI (Lifted Index) = - 06; SI (Showalter Index) = - 0.7; K Index = 36.7; $T T$ (Total Totals) = 43.9. The heaviest rainfall occured in the western region of Jakarta until Tangerang. Stagnant water is almost evenly in Jakarta and Tangerang with varying heights between $20 \mathrm{~cm}-100 \mathrm{~cm}$.
\end{abstract}

\section{Intisari}

DKI Jakarta dikejutkan dengan hujan deras pada jam 16:00 WIB. Genangan air langsung terjadi akibat derasnya hujan. Hujan berlangsung sampai sekitar jam 20:00 WIB. Dari data AWS di Jatiwaringin, curah hujan tertinggi sebesar $230 \mathrm{~mm}$ tercatat pada jam 16:00 WIB. Curah hujan sampai jam 19:00 WIB tercatat sebesar $650.60 \mathrm{~mm}$ atau intensitas $216.87 \mathrm{~mm} / \mathrm{jam}$ untuk periode jam 16:00 s.d. 19:00 WIB. Beberapa indeks stabilitas, yang dihitung dari data rawinsonde jam 07:00 WIB, menunjukan potensi terjadinya aktivitas konvektif yang bisa menghasilkan hujan deras. Beberapa indeks stabilitas yang menunjukan potensi terjadinya proses konvektif kuat adalah: LI (Lifted Index) = - 06; SI (Showalter Index) = - 0.7; $\mathrm{K}$ Index = 36.7; TT (Total Totals) = 43.9. Kejadian hujan paling deras di kawasan barat DKI Jakarta sampai Tangerang. Genangan air hampir merata di DKI Jakarta dan Tangerang dengan ketinggian yang bervariasi antara $20 \mathrm{~cm}-100 \mathrm{~cm}$.

Kata kunci : Intensitas hujan, rawinsonde, radar cuaca, awan konvektif, banjir.

\section{PENDAHULUAN}

Pada tanggal 25 Oktober 2010 sekitar jam 16:00 WIB, Jakarta dikejutkan dengan hujan yang sangat deras disertai kilat dan guntur. Dalam tempo yang sangat singkat, genangan air sudah mulai tampak. Kejadian hujan hampir bersamaan dengan waktu pulang karyawan sehingga lalulintas di Jakarta dapat dikatakan lumpuh. Hujan deras yang mengakibatkan visibility kurang dari $10 \mathrm{~m}$ (pengalaman pribadi), volume kendaraan yang sangat besar, serta mulai adanya genangan air memperburuk kondisi lalu lintas. Sebagai akibatnya, banyak karyawan yang terjebak macet dan baru sampai ke rumah hampir tengah malam.

\footnotetext{
${ }_{1}^{1}$ Peneliti Madya - UPT Hujan Buatan, BPPT, Thamrin No. 8 Jakarta, email mkarmini@yahoo.com
}

Menurut Vivanews tanggal 25 Oktober 2010, jam 17:05 WIB (metro-vivanews 1), genangan air sampai jam 16:30 WIB terdapat di: Jl. Sudirman 50 cm (depan Ratu Plaza); sekitar Gd. Wika Cawang genangan air antara $20-40 \mathrm{~cm}$; di bawah fly over Cawang genangan $50 \mathrm{~cm}$; depan Gd. Depnaker, Gatot Subroto genangan $50 \mathrm{~cm}$; Kawasan SCBD genangan $50 \mathrm{~cm}$; bahkan di jalan $\mathrm{H}$. Saidi, Ciledug genangan air dilaporkan mencapai $100 \mathrm{~cm}$. Dengan kondisi seperti ini, lalu lintas hampir macet total di seluruh wilayah Jakarta karena banyak kendaraan yang tidak bisa melewati genangan air tersebut. Beberapa daerah di Jakarta Barat dan Jakarta Selatan masih mengalami genangan air dengan ketinggian yang bervariasi antara $10-50$ cm (Vivanews, 26 Oktober 2010 jam 08:32 WIB (metro-vivanews 2). 
Hujan dengan intensitas tinggi sekitar 3 jaman mengindikasikan bahwa hujan berasal dari awan konvektif yang cukup besar. Untuk melihat apa yang terjadi dengan kondisi cuaca pada tanggal 25 Oktober 2010, kami mengumpulkan beberapa data untuk dianalisa.

Tulisan ini akan menyajikan analisis kondisi cuaca pada tanggal 25 Oktober 2010.

\section{DATA YANG DIGUNAKAN}

Data yang akan digunakan untuk analisis kondisi cuaca terdiri dari: radar cuaca di Serpong yang dikelola oleh HARIMAU; data rawinsonde yang diluncurkan di Cengkareng pada tanggal 25 Oktober 2010, jam 07:00 WIB; dataAWS (Automatic Weather Station) yang berlokasi di Jatiwaringin (60 15.1 LS, 1060 54.5 BT) dan citra satelit.

\section{PEMBAHASAN}

\subsection{Data Rawinsonde}

Rawinsonde adalah alat pengukur parameter atmosfer secara vertikal. Rawinsonde diluncurkan di Cengkareng 2 kali setiap hari yaitu jam 07:00 dan 19:00 WIB. Data yang akan dianalisis adalah data tanggal 25 Oktober jam 07:00 WIB. Data tekanan udara, suhu, arah dan kecepatan angin secara vertikal di proses dengan program RAOB akan menghasilkan plot suhu udara dan suhu titik embun, arah dan kecepatan angin untuk berbagai ketinggian (tekanan udara). Selain plot, dalam analisis ini adalah skewT-log $\mathrm{p}$, akan diperoleh juga beberapa indek stabilitas atmosfer yang dapat menggambarkan kondisi atmosfer saat pengukuran dilakukan.

Data tanggal 25 Oktober 2010, jam 07:00 menghasilkan gambar skew $T-\log p$ seperti yang tampak dalam Gambar 1. Beberapa indek stabilitas adalah: $\mathrm{LI}=-0.6 ; \mathrm{SI}=-0.7 ; \mathrm{KI}=35.7 ; \mathrm{TT}=43.9$.

a. LI (Lifted Index) yang dikembangkan oleh Galway (1956), sangat bermanfaat dalam memprediksi kemungkinan terjadinya severe thunderstorm. Kemungkinan terjadinya severe thunderstorm sangat tinggi apabila nilai $\mathrm{LI} \leq-0.6$. (profhorn.aos. wisc.edu). Hasil rawinsonde tanggal 25 Oktober 2010 menunjukan bahwa nilai $\mathrm{LI}=-0.6$.

b. SI (Showalter Index) yang dikembangkan oleh Showalter (1947) merupakan indikator yang sederhana untuk mengukur tingkat stabilitas atmosfer. Bila nilai SI positif, maka kondisi atmosfer stabil (profhorn.aos.wisc edu). Hasil analisis rawinsonde menunjukan bahwa nilai $\mathrm{SI}=-0.7$.

c. KI dikembangkan oleh George (1960) menjadi indikator yang baik tentang kemungkinan terjadinya air mass thunderstorm (profhorn.aos.wisc.edu). Air mass thunderstorm adalah thunderstorm yang tidak diasosiasikan dengan kehadiran front, yaitu pertemuan dua massa udara (weather.weatherbug.com). Thunderstorm ini mempunyai tiga ciri: mempunyai life cycle singkat, terisolasi (tidak embeded), dan tidak terlalu membahayakan. $\mathrm{KI}$ antara 31 -35 menunjukan bahwa kemungkinan terjadi air mass thunderstorm sebesar 60 $80 \%$. KI tercatat sebesar 35.7 pada tanggal 25 Oktober.

d. TT, yang dikembangkan oleh Miller (1972), menunjukan apakah kondisi atmosfer mendukung untuk berkembangnya severe thunderstorm (profhorn.aos.wisc.edu). Bila nilai TT $\geq 48$, maka kondisi atmosfer sangat mendukung untuk berkembangnya severe thunderstorm. TT pada tanggal 25 Oktober tercatat sebesar 43.9.

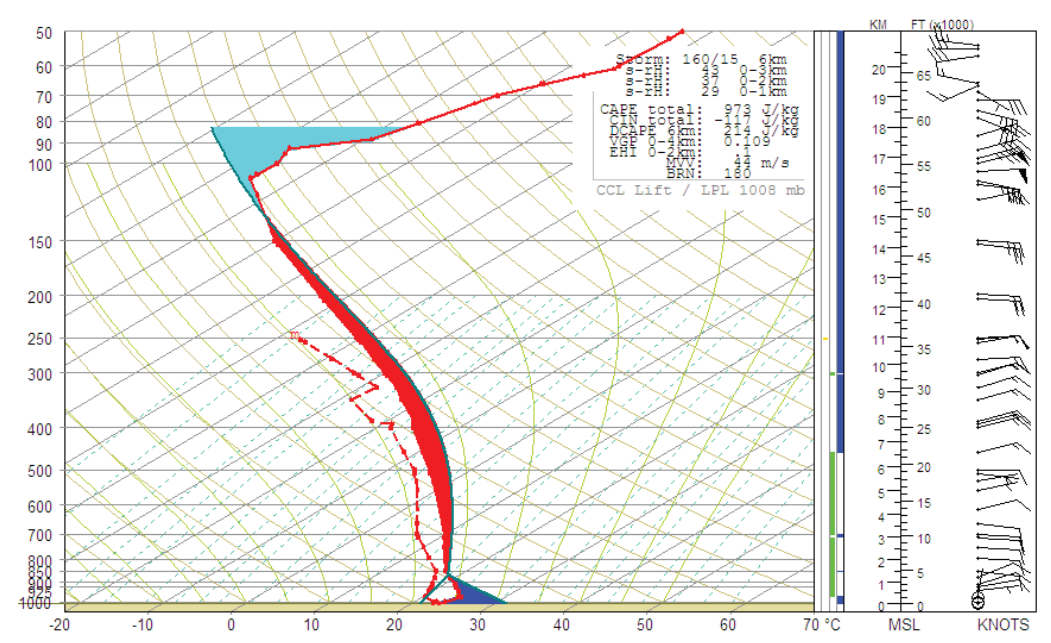

Gambar 1. Hasil ploting parameter suhu udara (red solid line) dan titik embun (garis putus-putus), serta arah dan kecepatan angin pada diagram Skew T - log p tanggal 25 Oktober jam 07:00 WIB. Suhu convektif $(\mathrm{TC})=320 \mathrm{C}$, 


\subsection{Data Radar Cuaca}

C-Band Doppler radar berlokasi di PUSPIPTEK Serpong, Jakarta $\left(6.4^{\circ}\right.$ LS, $106.7^{\circ}$ BT). Radar ini merupakan bagian dari proyek HARIMAU yang mana merupakan kerjasama antara JAMSTEC dan BPPT. Citra radar yang digunakan adalah CAPPI reflektivitas untuk ketinggian $2 \mathrm{~km}$. Citra radar dapat di download dari http://turbulence. ddo.jp/index.html.

a. Citra radar tanggal 25 Oktober 2010, jam 09:29 WIB.

Gambar 2 menunjukan bahwa pada jam 09:29 WIB belum tampak adanya pertumbuhan awan. Udara masih dapat dikatakan clear dari awan. Kecepatan angin juga dapat dikatakan lemah.

b. Citra radar jam 12:23 WIB.

Awan cumulus $(\mathrm{Cu})$ sudah mulai tampak pada Gambar 3, yaitu di sekitar Teluk Jambe dan sektor selatan pada citra radar. Akan tetapi, di sekitar Jakarta Barat, Selatan dan Tangerang, kondisi cuaca tampaknya masih clear.

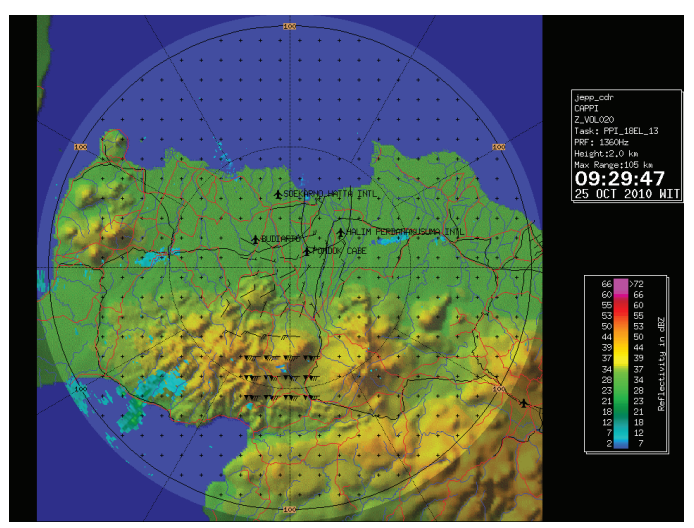

Gambar 2. Citra radar (CAPPI untuk ketinggian $2 \mathrm{~km}$ ) tanggal 25 Oktober 2010, jam 09:29 WIB.

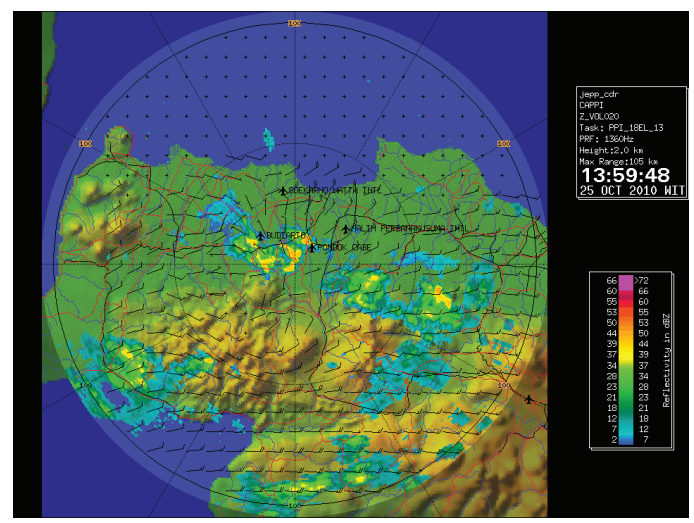

Gambar 4. Seperti Gambar 2 untuk jam 13:59 WIB. c. Citra radar jam 13:59 WIB.

Pada jam 13:59 awan $\mathrm{Cu}$ aktif sudah tampak di sekitar Jonggol, Pondok Cabe dan Curug, selain yang di sektor selatan (Gmb. 4). Kondisi seperti ini menunjukan bahwa awan $\mathrm{Cu}$ tumbuh akibat kuatnya proses konvektif di daerah tersebut. Reflektivitas di sekitar Pondok cabe menunjukan nilai sekitar $53 \mathrm{dBz}$ yang berarti kandungan air dalam awan tersebut sangat tinggi.

d. Citra radar jam 14:59 WIB.

Jam 15:00 WIB sudah terjadi hujan di sebagian wilayah seperti halnya di Jatiwaringin dan Curug. Awan cumulonimbus ( $\mathrm{Cb})$ sudah memasuki wilayah Jakarta Pusat sementara awan $\mathrm{Cb}$ yang di sekitar Pondok Cabe masih tetap ada (Gambar 5). Angin terpantau tidak terlalu kencang. Hujan deras di sekitar jalan protokol, tol dalam kota dan sekitarnya terjadi sekitar jam 16:00 WIB. sekitar jalan protokol, tol dalam kota dan sekitarnya terjadi sekitar jam 16:00 WIB.

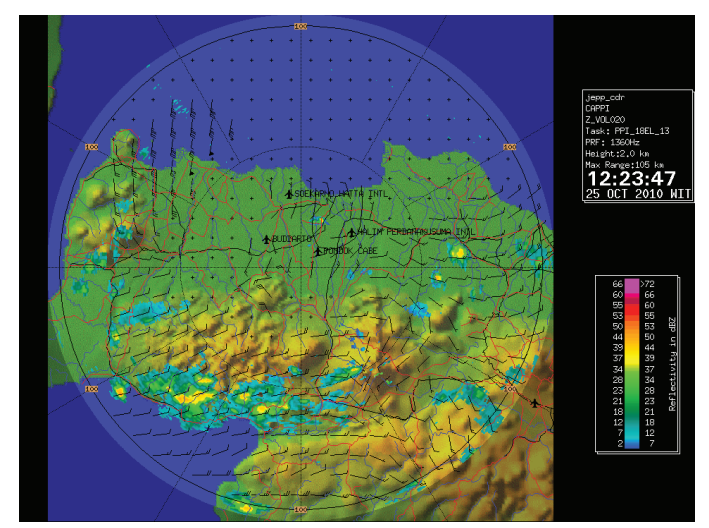

Gambar 3. Seperti Gambar 2 untuk jam 12:23 WIB.

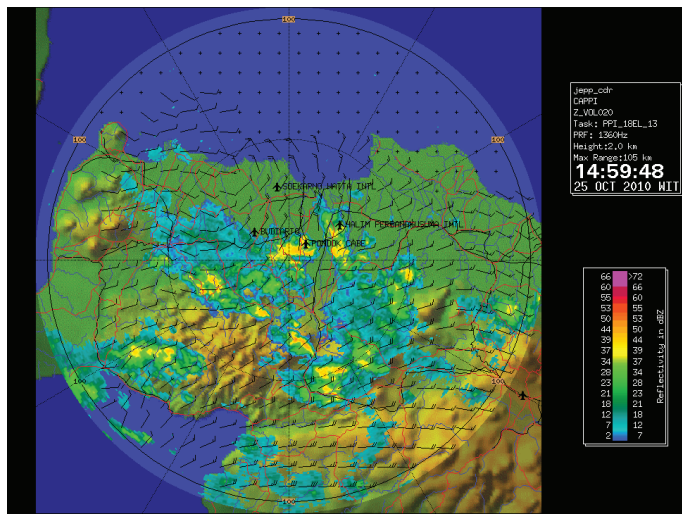

Gambar 5. Seperti Gambar 2 untuk jam 14:59 WIB. 


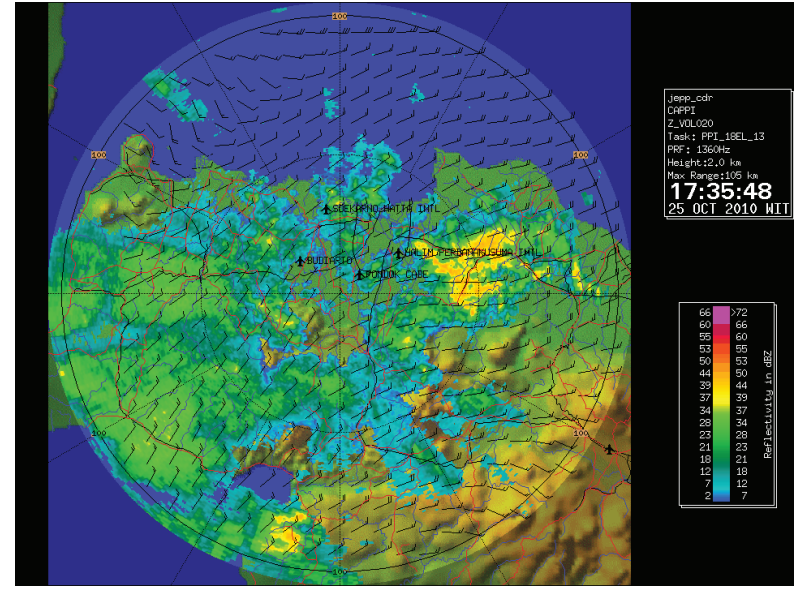

Gambar 6. Seperti Gambar 2 untuk jam 17:35 WIB.

e. Citra radar jam 17:35 WIB.

Pada jam 17:35 awan $\mathrm{Cb}$ yang tampak pada Gambar 5 sudah turun sebagai hujan yang deras seperti tampak pada Gambar 6. Reflektivitas yang tampak merupakan awan stratus (nimbostratus) meskipun reflektivitas masih tampak tinggi $(44 \mathrm{dBz})$ di sekitar wilayah Bekasi. Hal ini menunjukan bawhwa awan nimbostratus cukup tebal dan masih mengandung banyak air.

\subsection{Data Citra Satelit.}

Citra satelit diambil dari Kochi University Jepang dengan situs: http://weather.is.kochi-u. ac.jp/SE/00Latest.jpg. Situs ini menyediakan citra satelit kanal infra merah untuk wilayah Asia Tenggara yang diterbitkan tiap jam. Gambar 7 menunjukan citra satelit jam 16:00 WIB di mana hujan di wilayah DKI Jakarta sangat deras. Tampak bahwa awan yang ada sekitar Jawa Barat, DKI Jakarta dan Banten merupakan awan Cb (dicirikan dengan bentuknya)

\subsection{Data AWS.}

AWS (Automatic Weather Station) mencatat data suhu udara, tekanan permukaan, curah hujan dan angin permukaan secara kontinu. Akan dilihat profil suhu permukaan yang mana dapat menunjukan apakah suhu konvektif yang dianalisa dari data rawinsonde tercapai pada tanggal 25 Oktober 2010? Jika suhu konvektif tercapai atau bahkan terlampaui, maka nilai indek stabilitas akan sangat berarti. Waktu kejadian hujan dan besarnya jumlah curah hujan juga dapat diketahui. Profil tekanan udara permukaan terhadap waktu akan menunjukkan berapa besar perubahan tekanan saat terjadi proses konvektif dan saat terjadi hujan.

a. Data suhu udara permukaan.

Suhu konvektif Tc $\left(32^{\circ} \mathrm{C}\right)$ sudah dicapai sekitar jam 11:30 WIB. Suhu permukaan tertinggi adalah $33.5^{\circ} \mathrm{C}$ yang terjadi sekitar jam 13:30 WIB (Gambar 8). Hal ini menunjukan bahwa radiasi matahari sangat kuat. Dengan dilampauinya suhu Tc, maka proses konvektif berlangsung. dan nilai LI, $\mathrm{SI}, \mathrm{KI}$, dan TT yang mengindikasikan akan terjadi awan $\mathrm{Cb}$ (thunderstorm) dapat dijadikan pedoman bagaimana kuatnya awan $\mathrm{Cb}$ pada tanggal 25 Oktober yang lalu.

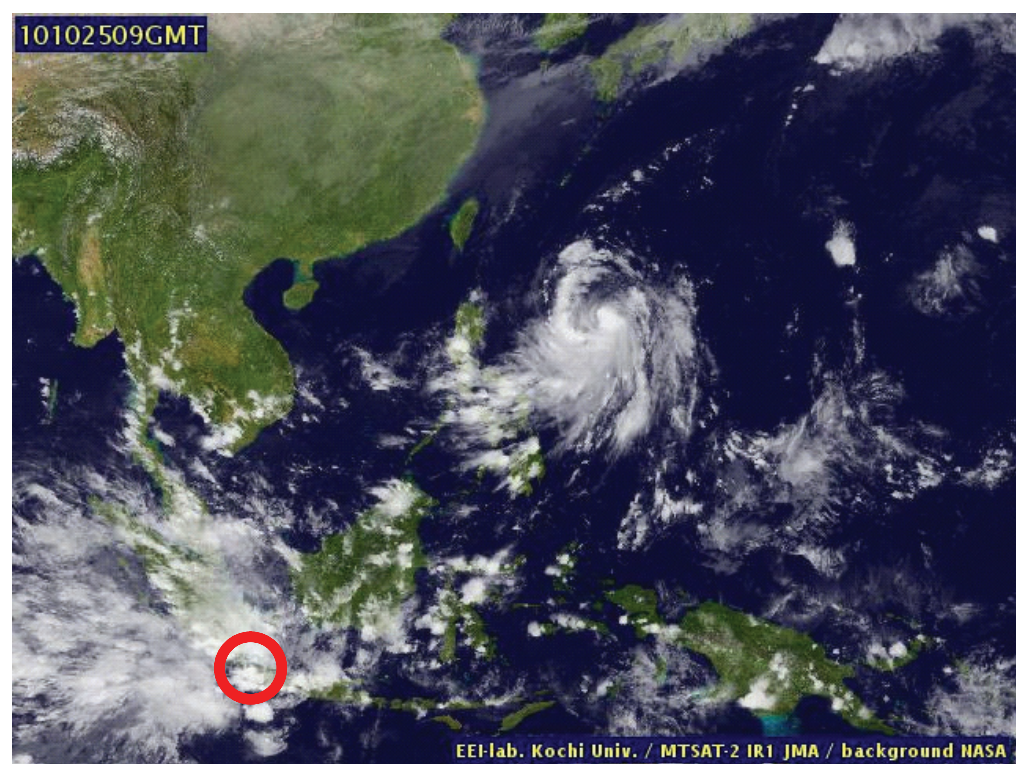

Gambar 7. Citra satelit kanal visible untuk tanggal 25 Oktober, jam 16:00 WIB. Tanda lingkaran merah menunjukan wilayah DKI Jakarta dan Sekitarnya. 


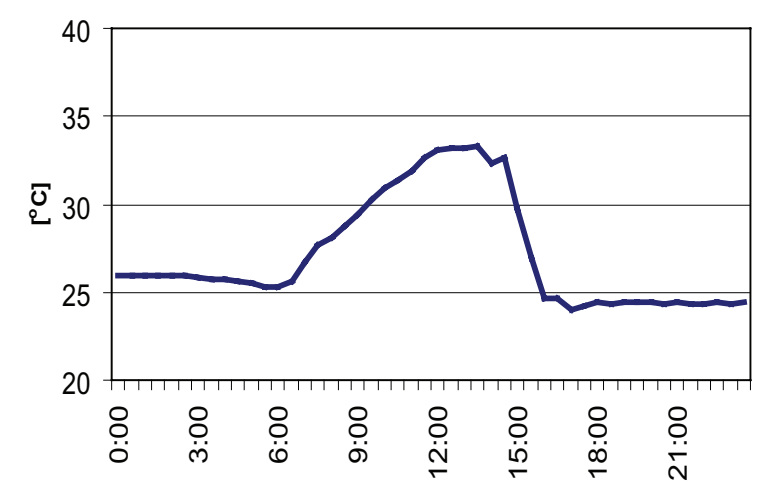

Gambar 8. Profil suhu udara permukaan tanggal 25 Oktober 2010.

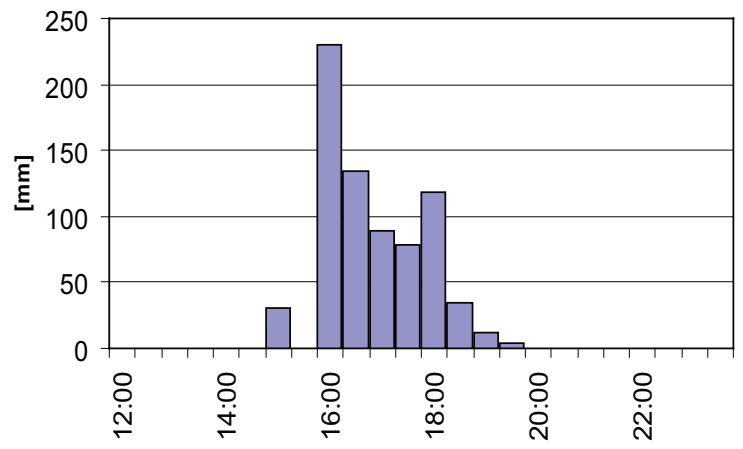

Gambar 9. Grafik curah hujan terhadap waktu, tanggal 25 Oktober 2010.

b. Data curah hujan.

Grafik curah hujan dapat dilihat pada Gambar 9. Hujan mulai turun di Jatiwaringin sekitar jam 15:00 WIB dengan jumlah sebesar $30.6 \mathrm{~mm}$. Hujan berhenti jam 15:30 WIB selama setengah jam. Jam 16:00 terjadi hujan sangat deras dengan curah hujan tercatat sebesar $230 \mathrm{~mm}$ dalam tempo setengah jam. Hujan berlangsung sampai jam 20:00 WIB. Curah hujan dari jam 16:00 s.d. jam 19:00 WIB tercatat sebesar $650.6 \mathrm{~mm}$, dengan kata lain intensitas curah hujan antara jam 16:00 s.d. 19:00 WIB sebesar $216.87 \mathrm{~mm} / \mathrm{jam}$.

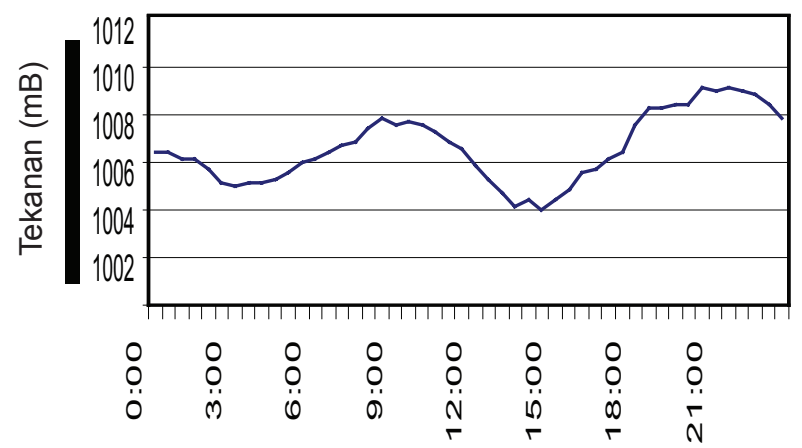

Gambar 10. Grafik tekanan udara permukaan tanggal 25 Oktober 2010. c. Data tekanan udara permukaan.

Tekanan udara permukaan berkisar pada nilai $1008 \mathrm{mb}$. Saat proses konvektif sangat aktif, tekanan udara turun sampai mencapai $1006 \mathrm{mb}$, atau turun sebesar $2 \mathrm{mb}$ (Gambar 10). Hujan di Jatiwaringin mulai jam 15:00 WIB, dan tekanan udara mulai menunjukan kenaikan pada jam 15:00 WIB. Tekanan udara paling tinggi tercatat sebesar $1011 \mathrm{mb}$, dengan kata lain terjadi kenaikan tekanan udara sebesar $5 \mathrm{mb}$ dalam tempo 6 jam.

\section{KESIMPULAN}

Dari hasil analisis data yang ada, kondisi cuaca dan kejadian hujan tanggal 25 Oktober 2010 dapat disimpulkan sebagai berikut.

- $\quad$ Awan $\mathrm{Cb}$ yang menyebabkan curah hujan tinggi dapat dikategorikan sebagai air mass thunderstorm.

- $\quad$ Proses pertumbuhan awan didominasi oleh proses konvektif yang dimulai sejak jam 11:30 WIB.

Kondisi atmosfer tidak stabil dan sangat mendukung pertumbuhan awan $\mathrm{Cb}$. Hal ini tercermin dari nilai LI, SI dan TT.

- Intensitas hujan sebesar $216.87 \mathrm{~mm} / \mathrm{jam}$ dalam periode 3 jam menyebabkan genangan air terjadi di beberapa wilayah DKI Jakarta dan Tangerang, Banten.

\section{Ucapan Terimakasih}

Penulis mengucapkan terimakasih yang setinggi-tingginya kepada Proyek HARIMAU yang telah memperbolehkan kami menggunakan data citra radar C-Band Doppler radar di PUSPIPTEK, Serpong.

\section{DAFTAR PUSTAKA}

Galway, J. G., 1956: The lifted index as a predictor of latent instability. Bull. Amer. Meteor. Soc., 528-529.

George, J. J., 1960: Weather Forecasting for Aeronautics, Academic Press, 673 pp Showalter, A. K., 1947: A stability index for forecasting thunderstorms. Bull. Amer. Meteor. Soc., 34, 250- 252.

Miller, R. C., 1972: Notes on analysis and severe storm forecasting procedures of the Air Force Global Weather Central. Tech. Rept. 200(R), Headquarters, Air Weather Service, USAF, $190 \mathrm{pp}$. 


\section{SITUS}

http://metro.vivanews.com/news/read/184873sudirman-banjir-setengah-meter--macettotal

http://metro.vivanews.com/news/read/184968hingga-pagi-ini-banjir-masih-genangi-jakarta http://profhorn.aos.wisc.edu/wxwise/ AckermanKnox/chap11/TW_Index.html http://weather.is.kochi-u.ac.jp/SE/00Latest.jpg

http://weather.weatherbug.com/weatherglossary/A/Air\%20Mass\%20Thunderstorm. html 